\title{
In vivo measurement of intragastric pressure with a rubber balloon in the anaesthetized rat
}

\begin{tabular}{|r|l|}
\hline Journal: & Current Protocols \\
\hline Manuscript ID: & CP-13-0046 \\
\hline Wiley - Manuscript type: & Protocol \\
\hline Complete List of Authors: & $\begin{array}{l}\text { Zádori, Zoltán; Semmelweis University, Department of Pharmacology and } \\
\text { Pharmacotherapy } \\
\text { Gyires, Klára; Semmelweis University, Department of Pharmacology and } \\
\text { Pharmacotherapy }\end{array}$ \\
\hline Abstract: & $\begin{array}{l}\text { Stomach, intragastric pressure, rubber balloon, anaesthetized rat } \\
\text { the fundus after laparotomy. The effects of both stimulatory (e.g. } \\
\text { carbachol) and inhibitory (e.g. oxymetazoline) agents can be evaluated on } \\
\text { the gastric tone and phasic contractions. The model allows the evaluation } \\
\text { of dose-response curves and also the time-course of the effects. } \\
\text { Furthermore, by combining centrally or peripherally acting agents the site } \\
\text { of action can also be determined. }\end{array}$ \\
\hline \\
\hline
\end{tabular}

\section{SCHOLARONE ${ }^{\text {w }}$ \\ Manuscripts}


In vivo measurement of intragastric pressure with a rubber balloon in the anaesthetized rat

\author{
Zoltán S. Zádori and Klára Gyires \\ Department of Pharmacology and Pharmacotherapy, Faculty of Medicine, Semmelweis \\ University, Nagyvárad tér 4, 1089, Budapest, Hungary
}

\title{
Corresponding author:
}

Zoltán S. Zádori

Department of Pharmacology and Pharmacotherapy, Semmelweis University, Nagyvárad tér 4., 1089, Budapest, Hungary

Phone: 36-1-210-4416

Fax: 36-1-210-4412

e-mail: zadzol@net.sote.hu 


\begin{abstract}
The protocols described in this unit are designed to measure the intragastric pressure in anaesthetized rats by a water-filled low-compliance rubber balloon. The balloon is introduced into the stomach either orally (by passing the balloon down the esophagus) or directly via a small incision of the fundus after laparotomy. The effects of both stimulatory (e.g. carbachol) and inhibitory (e.g. oxymetazoline) agents can be evaluated on the gastric tone and phasic contractions. The model allows the evaluation of dose-response curves and also the timecourse of the effects. Furthermore, by combining centrally or peripherally acting agents the site of action can also be determined.
\end{abstract}

Keywords: stomach, intragastric pressure, rubber balloon, anaesthetized rat 


\section{Introduction}

There are several in vivo and in vitro methods to measure gastrointestinal (GI) motor activity. In vitro methods (conducted either on whole isolated organs, whole intestinal segments or on circular or longitudinal muscle strips) allow direct evaluation of muscle functions without the influence of external factors (e.g. hormones or extrinsic nerves). They are particularly useful to determine concentration-response relationships, to measure and compare the potencies and efficacies of varies drugs or to analyze agonist-antagonist interactions. However, their main limitation is that the effect of a drug observed under in vitro conditions does not automatically reflect the drug's ,real” effect measured in vivo, in intact animals (or humans). The NK1 receptor agonist GR 73,632, for instance, dose-dependently suppresses the distension-induced duodenal contractions in vivo, but induces a biphasic response consisting of a transient, tetrodotoxin-sensitive inhibitory effect followed by tetrodotoxin-resistant contractions in vitro (Lecci et al., 1999). An other example is morphine, which constricts the ileal circular muscles in vitro, but inhibits intestinal transit in vivo (Iwata et al., 2007). Thus, to determine the net effect of a drug on GI motility, in vivo methods conducted in living animals cannot be omitted. There are numerous techniques to determine the GI motor activity in both conscious and anesthetized animals. Strain gauge force transducers can be implanted in the seromuscular layer of the GI tract to directly measure muscle contractions (Takahashi et al., 2007), or the movement of solid or fluidal contents (e.g. charcoal suspension or phenol red) in the stomach and intestines can be analyzed to determine gastric emptying or GI transit (Scheibner et al., 2002; Fülöp et al., 2005).

A further possibility is the rubber balloon method; a simple and reliable technique to determine GI motor activity by measuring changes in the intraluminal pressure. This method has been commonly used since the beginning of the 20th century (Bayliss and Starling, 1899; Langley and Magnus, 1905), and its main principle is that pressure changes due to contractions of the gut wall can be registered by an intraluminal low-compliance balloon, which is either air- or fluid-filled and connected to a pressure transducer via a plastic tube. This method can be used in different species (e.g. rats, rabbits, cats, dogs) and in any part of the GI tract, like the stomach (Ferreira Jr. et al., 2002; Zádori et al., 2007), or small and large intestines (Takeuchi et al., 2002; Umezawa et al., 2003). Moreover, although the method is mainly used to test GI motility in animals under general anesthesia, it can also be adapted to conscious animals (Hoebel, 1967).

This unit describes the measurement of intragastric pressure in anesthetized rats. The balloon is introduced into the stomach either non-invasively, via the mouth (as described e.g. by Hoebel, 1967; LeFebvre et al., 1992) (see Basic Protocol), or via a small incision of the fundus (Nagata and Osumi, 1990; Ferreira Jr. et al., 2002) or duodenum (Zhou et al., 2008) after laparotomy (see Alternate Protocol).

NOTE: All protocols using living animals must first be reviewed and approved by an Institutional Animal Care and Use Committee (IACUC) or local equivalent and must conform to governmental regulations regarding care and use of laboratory animals. 


\section{Basic Protocol}

\section{Measurement of intragastric pressure by introducing the balloon via the mouth}

The following protocol is designed to assess the intragastric pressure of anesthetized rats by introducing the rubber balloon into the stomach via the mouth. Test compounds are usually given intravenously, but other routes of administration (e.g. direct injection into the central nervous system, Krowicki and Hornby, 2000; Brancati et al., 2013) are also possible.

\section{Materials list}

- Solutions and reagents

- $25 \%(\mathrm{w} / \mathrm{v})$ urethane (see recipe)

- $\quad 0.9 \%(\mathrm{w} / \mathrm{v}) \mathrm{NaCl}$ (physiological saline, see recipe)

- test compounds (carbachol, oxymetazoline, see recipe)

- Special materials and equipments

- male Wistar rats $(250$ - $350 \mathrm{~g})$

- standard rodent food

- solid-bottom polypropylene cages (with minimum $800 \mathrm{~cm}^{2}$ floor area to house the animals in access-restricted temperature/light-controlled rooms)

- mesh-bottom rodent cages (to house the animals before experiments)

- $\quad$ animal scale (accuracy \pm 1 g, e.g. Mettler Toledo)

- surgical equipments (a sharp scissor, two small curved forceps, surgical needles)

- latex condom

- esophageal catheter $(\sim 15-20 \mathrm{~cm}$ long polyethylene tube with beveled end and $1 \mathrm{~mm}$ diameter)

- stainless steel wire (fitting in the esophageal cannula)

- tracheal cannula ( $\sim 2-3 \mathrm{~cm}$ long plastic tube with $2 \mathrm{~mm}$ diameter)

- venous cannula ( $4-5 \mathrm{~cm}$ polyethylene tube (PE-50) attached to a $22-\mathrm{G}$ blunt needle)

- heated surgery table for rats (e.g. 2Biological Instruments)

- rectal temperature probe

- polyethylene tubes ( $2 \mathrm{~mm}$ diameter)

- tube clamps and connectors (e.g. Harvard Apparatus)

- graduated glass pipette ( $\geq 30 \mathrm{~cm}$, with $1 \mathrm{~mm}$ scale)

- laboratory stands and clamps (e.g. Cole-Parmer)

- recording apparatus including:

$\circ$ pressure transducer (e.g. ADInstruments)

$\circ$ bridge amplifier (e.g. ADInstruments, Model FE221)

- a PC-based data acquisition system (e.g. ADInstruments, PowerLab 4/35 with LabChart Software) 
- Standard laboratory equipments

- latex surgical gloves

- 2-ml plastic syringes

- 25-G needles

- cotton thread

- paper towels

\section{Protocol steps}

\section{Prepare the intragastric balloon}

1. Cut off the end $(\sim 4-5 \mathrm{~cm})$ of a latex condom, and tie it around the esophageal catheter with a cotton thread, approximately $3 \mathrm{~cm}$ from the end of the catheter (= length of the balloon). The rest of the condom can be removed.

Alternatively, fingertips of surgical gloves can also be used (Ferreira Jr. et al., 2002; Palheta et al., 2010).

2. Test the balloon for leaks by inflating the catheter with $2-3 \mathrm{ml}$ distilled water.

This test should be made before and after every experiment.

3. Store the balloon in distilled water (for example in a conical flask), if the setup is not used.

This way the balloon won't dry out and can be used for several weeks.

\section{Prepare the setup for pressure measurement}

4. Clamp the graduated glass pipette and the pressurue transducer to laboratory stands, and connect the lower end of the pipette to the transducer with a polyethylene tube. Fill up the system with distilled water, avoid bubbles.

5. Connect the pressure transducer to the bridge amplifier and data acquisition system (Fig. 1).

\section{Induce anesthesia and cannulate the trachea and a femoral vein}

6. Purchase male Wistar rats, weighing $200-250 \mathrm{~g}$.

Other strains, e.g. Sprague-Dawley rats are also suitable (Table 1). 
7. Acclimate the animals in solid-bottom cages (max. five animals per cage) for 1 week in the animal housing facility under standard lighting (12-12 h light/dark cycle) and temperature $\left(22-23{ }^{\circ} \mathrm{C}\right)$ conditions. Provide them food (standard pellet diet) and water ad libitum.

8. $24 \mathrm{hr}$ before the experiment deprive the animals of food, but allow free access to water. Put them in mesh-bottom cages, allowing feces to fall down and thus avoiding coprophagy.

9. Weigh a rat using an animal scale accurate to $1 \mathrm{~g}$ and anesthetize the animal with intraperitoneal (i.p.) injection of urethane $(1.25 \mathrm{~g} / \mathrm{kg})$.

Inject $0.5 \mathrm{ml}$ per $100 \mathrm{~g}$ of body weight from the $25 \%(\mathrm{w} / \mathrm{v})$ solution. Complete anesthesia can be achieved within 5-10 minutes and lasts for several hours, thus additional anesthetic is not required.

10. Place the rat on its back on a heated surgery table, and insert a rectal temperature probe into the anus. Maintain the body temperature at $37^{\circ} \mathrm{C}$ during the whole experiment.

11. Perform tracheotomy to ensure a clear airway.

Cut the skin of the rat, and separate the longitudinal muscles in the midline with small curved forcepses to expose the trachea. Clean it from connective tissue, separate it from the esophagus and pass cotton thread under the trachea without tying. Make a small, horizontal incision between two tracheal cartilages, introduce the tracheal cannula gently into the lumen and tie it with the thread.

12. Cannulate one of the femoral veins.

This will be used for drug administration. Make a $\sim 2 \mathrm{~cm}$ skin incision between the leg and the abdomen. Expose the femoral vein by blunt dissection of the muscles. Separate it from the femoral artery and nerve. Pass two threads beneath the vein and tie the distal one tightly to occlude blood flow from the leg. Make a small incision on the vein and introduce the venous cannula filled with saline into the vessel. Tie the proximal thread around the cannula and vein tightly and flush the cannula with $0.1 \mathrm{ml}$ saline.

Other routes of administration (e.g. central or subcutaneous) are also possible.

\section{Introduce the balloon into the stomach}

13. Introduce the steel wire into the polyethylene esophageal catheter. The wire must fit loosely into the catheter so it can be withdrawn later. 
The wire holds the polyethylene esophageal catheter straight and helps to avoid it from bending back during the cannulation. It is essential to push the wire until the distal end of the catheter, without damaging the balloon.

14. Grab the tongue of the rat with a small forceps gently and open the animal's mouth by pulling the tongue out and to one side. Place the balloon-end of the catheter into the mouth, but avoid the teeth.

It may be useful to drop some water on the balloon, to reduce its adhesion to the tissues.

15. Hold the rat's head in straight position and push down the catheter.

Keep pushing the catheter, even if the animal may start swallowing. However, do not force the cannulation, because you can damage the esophageal wall and push the balloon into the mediastinal space, which usually leads to death of the animal. If you run into resistance, pull the catheter slightly back, and try from another angle. By holding the rat with two fingers above the diaphragm and two below, the balloon can be palpated as it enters the stomach (generally after inserting the catheter 13-15 cm).

16. Position the distal end of catheter toward the antrum by pushing it gently to the right side of the rat.

17. Pull the wire back and inject $1.5-2 \mathrm{ml}$ warm $\left(37^{\circ} \mathrm{C}\right)$ distilled water into the balloon slowly.

18. Connect the proximal end of catheter to the water-filled glass pipette via the pressure transducer (Fig. 1) and calibrate the system.

Clamp the tube between the balloon (rat) and the pressure transducer during the calibration process. Turn on the PC-based data acquisition system and start the recording program (e.g. LabChart). Record two pressure values within the expected range (see Anticipated results) by altering the height of the water column in the glass pipette and convert the recorded voltage values to the appropriate $\mathrm{CmH}_{2} \mathrm{O}$ values.

19. Set the baseline intragastric pressure to $10 \mathrm{cmH}_{2} \mathrm{O}$.

Though $10 \mathrm{cmH}_{2} \mathrm{O}$ is a commonly used baseline pressure value, studies vary at this point and both lower or higher values are used (see Table 1 and Background Information).

19. Wait 30-45 min for equilibration.

Basal intragastric pressure may increase or decrease within this time. Adjust it slowly to 10 $\mathrm{cmH}_{2} \mathrm{O}$ (repeatedly, if necessary). 


\section{Evaluate the effect of test compounds}

20. If basal intragastric pressure is stable and in the range of 9.5 to $10.5 \mathrm{cmH}_{2} \mathrm{O}$, the preparation is ready to test compounds (Fig. 2A).

In some cases the baseline pressure constantly decreases and does not equilibrate at 10 $\mathrm{CmH}_{2} \mathrm{O}$ despite of repeated water injection (Fig. 2B). This is usually caused by wrong localization of the balloon (either in the fundus, or outside of the stomach); discard these animals.

21. Dissolve test compounds in the appropriate vehicle and administer them intravenously (i.v.) in the volume of $0.1 \mathrm{ml} / 100 \mathrm{~g}$.

As mentioned above, alternative routes of administration are also possible.

22. At the end of experiment euthanize the animal and verify the exact location of the balloon. After removal of the balloon fill it with water to confirm absence of leakage.

Open the abdominal cavity of the rat by cutting the skin and the abdominal muscle layer in the midline. If the balloon is filled with water, its location can be easily verified.

23. Calculate the mean amplitude of phasic contractions and the mean of the lowest points of phasic pressure wave within 5 min periods before and after the administration of the test compounds (Fig. 2C).

The first parameter (mean amplitude of contractions) correlates with the antral contractions superimposed on tonic pressure, while the second (bottom points of pressure wave) correlates well with fundic activity (Ferreira Jr. et al., 2002; Shi et al., 2003; Li et al., 2006; Zádori et al., 2007).

If the effect of a substance on gastric motor activity is shorter in duration (e.g. it causes a rapid, temporary reduction of gastric tone followed by a secondary elevation), shorter calculation periods can also be used.

24. Calculate the percentage changes from baseline values.

It is more common to express the percentage changes of motility from baseline values than to use absolute values, because the measured values (especially the amplitudes of contractions) can markedly vary among animals.

\section{Alternate Protocol}

\section{Measurement of intragastric pressure by introducing the balloon via the fundus}


Alternatively, the rubber balloon can also be inserted into the stomach via a small incision of the fundus or duodenum after laparotomy. The main advantage of this protocol is that the location of the balloon can be positioned accurately before each experiment. On the other hand, exposing the stomach and making a small incision on its wall is less physiological and abdominal surgery may affect GI motor activity (Yuasa and Watanabe, 1994; Fukuda et al., 2005).

\section{Materials list}

For materials see Basic Protocol.

\section{Protocol steps}

1. Follow Basic Protocol up to step 13.

\section{Introduce the balloon into the stomach via a small incision of the fundus}

2. Cut the skin, then the abdominal muscle layer in a $\sim 2-3 \mathrm{~cm}$ length in the midline, over the linea alba. Use the xiphoid process as a reference point.

3. Expose the stomach and exteriorize it gently. Make a small incision on the fundus and introduce the balloon into the lumen of the stomach toward the antrum.

4. Close the stomach wall around the catheter with purse-string suture to secure it in place.

5. Inject $1.5-2 \mathrm{ml}$ warm $\left(37^{\circ} \mathrm{C}\right)$ distilled water into the balloon slowly.

6. Close the laparotomy.

7. Follow Basic Protocol from step 18.

\section{Reagents and Solutions}

Use Milli-Q-purified water or equivalent in all recipes and protocol steps.

\section{Carbamoylcholine chloride (Carbachol)}

Prepare a $1 \mathrm{mg} / \mathrm{ml}$ aqueous carbamoylcholine chloride (Sigma) stock solution and dilute 1:40 (v/v) in physiological saline on the day of use. Stock solution is stable for up to 6 months at $4^{\circ} \mathrm{C}$.

\section{Oxymetazoline hydrochloride}


Prepare a $1 \mathrm{mg} / \mathrm{ml}$ aqueous oxymetazoline hydrochloride (Sigma) stock solution and dilute $1: 2(\mathrm{v} / \mathrm{v})$ in physiological saline on the day of use. Stock solution can be stored at $20^{\circ} \mathrm{C}$ up to 1 month.

\section{Physiological saline $(0.9 \%(w / v) \mathrm{NaCl})$}

Dissolve $9 \mathrm{~g} \mathrm{NaCl}$ in $1000 \mathrm{ml}$ distilled water and store up to 1 week at room temperature.

\section{Urethane stock solution (25\% (w/v))}

Dissolve $25 \mathrm{~g}$ urethane (Sigma) in $100 \mathrm{ml}$ distilled water with stirring. Store up to 1 week at room temperature.

\section{Commentary}

\section{Background information}

Gastric motility is a complex and tightly regulated process, in which the spontaneous contractile activity of the smooth muscle cells (directly regulated by slow-wave potentials originating from interstitial cells of Cajal (ICC)) is influenced by circulating hormones and excitatory or inhibitory transmitters released from intrinsic and extrinsic neurons (Schemann et al., 2008). Gastric motor functions can be divided into two distinct activities. The proximal or fundal portion serves as a reservoir. It is relaxed upon food intake and maintains the intragastric pressure low. It produces slow, tonic contractions which gradually press the stomach content toward the distal (antral) part, which produces phasic contractions to mix and grind the ingested food. Various diseases and drugs can influence gastric motor activity and lead to accelerated or delayed gastric emptying. Increased gastric emptying (e.g. due to partial gastrectomy) may cause duodenal caloric overload and dumping syndrome, while decreased motility and emptying (for example in the cases of functional dyspepsia and gastroparesis, or as a consequence of anticholinergic medication) can lead to postprandial fullness, early satiation and gastric pain (Rose, 1979; Tack, 2008).

There are several techniques to assess gastric motility. One possibility is the rubber balloon method, with which intragastric pressure changes can be determined. This method is useful to analyze the effect of different stimulatory or inhibitory compounds on both intragastric tone (which mainly correlates with fundus activity) and antral phasic contractions (Ferreira Jr. et al., 2002; Shi et al., 2003). Because intragastric pressure can significantly differ among animals, it is suggested to standardize the resting intraluminal pressure at the beginning of the experiment as well as to calculate relative changes from baseline values instead of using absolute values. As Table 1 demonstrates, starting pressure values vary in different studies. Though all these values are within the physiological range (Baird et al., 2001; Min et al., 2011), it has to be taken into consideration that higher pressure values and 
the consequent distension of the stomach wall induces vago-vagal, sympatho-sympathetic and intramural reflexes (both excitatory and inhibitory) (Abrahamsson et al., 1973; Andrews et al., 1980; Ozaki et al., 1999), which can alter the motility pattern. Andrews et al. (1980) demonstrated that $3 \mathrm{cmH}_{2} \mathrm{O}$ intragastric pressure (but in some cases already $1 \mathrm{cmH}_{2} \mathrm{O}$ ) elicits vagally mediated antral contractions in urethane-anaesthetized ferrets. Ozaki et al. (1999) found that distension threshold in vagal afferent fibers vary between 0 and $18 \mathrm{Hgmm}$ (equal to 0-25 $\left.\mathrm{cmH}_{2} \mathrm{O}\right)$ in rats, with $5.3 \mathrm{Hgmm}\left(7.2 \mathrm{cmH}_{2} \mathrm{O}\right)$ mean threshold pressure.

The effect of drugs on gastric motility can also be analyzed under stimulated conditions. Stimulation of motility can be elicited either by central or peripheral mechanisms. For example 2-deoxy-D-glucose or insulin increase the activity of the vagal nerve, while muscarinic receptor agonists carbachol or betanechol act directly on gastric smooth muscles (Fülöp et al., 2005; Zádori et al., 2007). Stimulation of gastric motility at the beginning of the experiment can be useful, if inhibitory compounds (e.g. alpha-2 adrenoceptor stimulants) are tested. Moreover, the use of centrally or peripherally acting stimulatory agents can help to determine the site of action of the tested drugs.

It has long been known that presynaptic alpha-2 adrenoceptors located on cholinergic axon terminals play an important role in the regulation of GI functions by inhibiting the release of acetylcholine (Paton and Vizi, 1969). Careful pharmacological analyses and experiments on genetically engineered mice revealed that among the three alpha-2 adrenoceptor subtypes (alpha-2A, 2B, 2C) the alpha-2A subtype is predominantly expressed in the GI tract and is responsible for mediating most GI effects (Blandizzi, 2007; Gyires et al., 2009). Accordingly, administration of non-selective (clonidine, medetomidine) or alpha-2A adrenoceptor subtype selective agents (oxymetazoline) decreases both gastric tone and phasic antral contractions under basal and stimulated conditions. Moreover, these drugs are also decrease gastric emptying and inhibit gastric acid and gastrin secretion (Blandizzi, 2007).

\section{Critical parameters and troubleshooting}

Animals must be fasted before experiments, otherwise intragastric pressure changes cannot be measured accurately. Cannulation of trachea and femoral veins, and introduction of the balloon into the stomach via mouth require practice and some manual dexterity. Rat temperature should be maintained at $37^{\circ} \mathrm{C}$ during the whole experiment.

Since the method requires the use of general anesthesia, the effect of the anesthetic on gastric motility has also to be taken into consideration. Urethane is a long-acting anesthetic, which is widely used in gastrophysiology studies due to its presumptive sparing of autonomic function (see Table 1). However, i.p. injection of urethane elevates the blood glucose level, which in turn inhibits gastric emptying significantly due to reduction of gastric tone and antro-pyloric coordination (Yuasa and Watanabe, 1994; Takeuchi et al., 1994; QuallsCreekmore et al., 2010). Alternatively pentobarbital can be used, which has a shorter duration of action, but has only a little impact on GI motility (Reynell and Spray, 1957; Takeuchi et al., 1994). 
If the balloon is inserted into the stomach via mouth and baseline pressure cannot be set to $10 \mathrm{cmH}_{2} \mathrm{O}$ due to constant reduction of pressure after repeated water injection, the balloon is either in the fundus or outside of the stomach. In this case make a laparotomy and try to fix its position.

\section{Anticipated results}

After setting the baseline intragastric pressure to $10 \mathrm{cmH}_{2} \mathrm{O}$, it can slowly increase or decrease and may require some additional adjustments. Intragastric pressure usually stabilizes within 20-30 min and remains within the range of 9.5-10.5 $\mathrm{cmH}_{2} \mathrm{O}$. Amplitudes of basal contractions are generally between 0.1 and $0.4 \mathrm{cmH}_{2} \mathrm{O}$, but there can be significant differences among animals and higher or lowel values are also possible. It is suggested to calculate the percentage changes from baseline values instead of using absolute values.

Fig. 3 shows the effect of carbachol $(0.025 \mathrm{mg} / \mathrm{kg}$ i.v. $)$ and oxymetazoline $(0.5 \mathrm{mg} / \mathrm{kg}$ i.v.) on gastric tone and amplitude of phasic contractions. Injection of carbachol increases gastric tone and contraction amplitude immediately, reaching a plateau after 4-8 min. Inject carbachol slowly to avoid excessive cardiovascular parasympathetic symptoms. In contrast, injection of oxymetazoline and presynaptic activation of alpha-2A adrenoceptors results in a prompt and long-lasting reduction of gastric tone and amplitudes of contractions.

\section{Time considerations}

Surgical preparation requires 10-30 min (depending on the experience of investigator). Additional 30-45 min are necessary to equilibrate basal intragastric pressure. The duration of experiment depends on the type of study and on the applied drugs. Generally, a drug can be tested in 2-3 different doses in one animal, and the whole experiment lasts up to 3-4 hr, including data analysis and cleaning the materials.

\section{Literature cited}

Abrahamsson, H. 1973. Vagal relaxation of the stomach induced from the gastric antrum. Acta Physiol. Scand. 89:406-414.

Andrews, P.L., Grundy, D., and Scratcherd, T. 1980. Reflex excitation of antral motility induced by gastric distension in the ferret. J. Physiol. 298:79-84.

Baird, J.P., Travers, J.B., and Travers, S.P. 2001. Parametric analysis of gastric distension responses in the parabrachial nucleus. Am. J. Physiol. Regul. Integr. Comp. Physiol. 281:1568-1580.

Bayliss, W.M., and Starling, E.H. 1899. The movements and innervation of the small intestine. J. Physiol. 24:99-143. 
Blandizzi, C. 2007. Enteric alpha-2 adrenoceptors: pathophysiological implications in functional and inflammatory bowel disorders. Neurochem. Int. 51:282-288.

Brancati, S.B., Zádori, Z.S., Németh, J., and Gyires, K. 2013. Substance P induces gastric mucosal protection at supraspinal level via increasing the level of endomorphin-2 in rats. Brain Res. Bull. 91:38-45.

Cruz, M.T., Murphy, E.C., Sahibzada, N., Verbalis, J.G., and Gillis, R.A. 2007. A reevaluation of the effects of stimulation of the dorsal motor nucleus of the vagus on gastric motility in the rat. Am. J. Physiol. Regul. Integr. Comp. Physiol. 292:291-307.

Ferreira, M., Jr., Sahibzada, N., Shi, M., Panico, W., Niedringhaus, M., Wasserman, A., Kellar, K.J., Verbalis, J., and Gillis, R.A. 2002. CNS site of action and brainstem circuitry responsible for the intravenous effects of nicotine on gastric tone. $J$. Neurosci. 22:2764-2779.

Fukuda, H., Tsuchida, D., Koda, K., Miyazaki, M., Pappas, T.N., and Takahashi, T. 2005. Impaired gastric motor activity after abdominal surgery in rats. Neurogastroenterol. Motil. 17:245-250.

Fülöp, K., Zádori, Z., Rónai, A.Z., and Gyires, K. 2005. Characterisation of alpha2adrenoceptor subtypes involved in gastric emptying, gastric motility and gastric mucosal defence. Eur. J. Pharmacol. 528:150-157.

Gyires, K., Zádori, Z.S., Török, T., and Mátyus, P. 2009. alpha(2)-Adrenoceptor subtypesmediated physiological, pharmacological actions. Neurochem. Int. 55:447-453.

Hoebel, B.G. 1967. Intragastric balloon without gastric surgery for the rat. J. Appl. Physiol. 22:189-190.

Iwata, H., Tsuchiya, S., Nakamura, T., and Yano, S. 2007. Morphine leads to contraction of the ileal circular muscle via inhibition of the nitrergic pathway in mice. Eur. J. Pharmacol. 574:66-70.

Krowicki, Z.K., and Hornby, P.J. 2000. Substance P in the dorsal motor nucleus of the vagus evokes gastric motor inhibition via neurokinin 1 receptor in rat. J. Pharmacol. Exp. Ther. 293:214-221. 
Langley, J.N., and Magnus, R. 1905. Some observations of the movements of the intestine before and after degenerative section of the mesenteric nerves. J. Physiol. 33:34-51.

Lecci, A., De Giorgio, R., Barthó, L., Sternini, C., Tramontana, M., Corinaldesi, R., Giuliani, S., and Maggi, C.A. 1999. Tachykinin NK(1)receptor-mediated inhibitory responses in the guinea-pig small intestine. Neuropeptides 33:91-97.

Lefebvre, R.A., Hasrat, J., and Gobert, A. 1992. Influence of NG-nitro-L-arginine methyl ester on vagally induced gastric relaxation in the anaesthetized rat. Br. J. Pharmacol. 105:315-320.

Li, Y.Q., Zhu, B., Rong, P.J., Ben, H., and Li, Y.H. 2006. Effective regularity in modulation on gastric motility induced by different acupoint stimulation. World J. Gastroenterol. 12:7642-7648.

Min, D.K., Tuor, U.I., and Chelikani, P.K., 2011. Gastric distention induced functional magnetic resonance signal changes in the rodent brain. Neuroscience 179:151-158.

Nagata, M., and Osumi, Y., 1993. Central alpha 2-adrenoceptor-mediated inhibition of gastric motility in rats. Jpn. J. Pharmacol. 62:329-330.

Ozaki, N., Sengupta, J.N., and Gebhart, G.F. 1999. Mechanosensitive properties of gastric vagal afferent fibers in the rat. J. Neurophysiol. 82:2210-2220.

Palheta, R.C., Jr., Rola, F.H., Lira, G.H., Gomes, D.A., Carvalho, F.M., Elias, L.L., AntunesRodrigues, J., Oliveira, R.B., and Santos, A.A. 2010. Atrial stretch increases the gastric tonus of anesthetized rats. Life Sci. 86:441-447.

Paton, W.D., and Vizi, E.S. 1969. The inhibitory action of noradrenaline and adrenaline on acetylcholine output by guinea-pig ileum longitudinal muscle strip. Br. J. Pharmacol. $35: 10-28$.

Qualls-Creekmore, E., Tong, M., and Holmes, G.M. 2010. Gastric emptying of enterally administered liquid meal in conscious rats and during sustained anaesthesia. Neurogastroenterol. Motil. 22:181-185.

Reynell, P.C., and Spray, G.H. 1957. The effect of ether and pentobarbitone sodium on gastrointestinal function in the intact rat. Br. J. Pharmacol. 12:104-106. 
Rose, E.F. 1979. Factors influencing gastric emptying. J. Forensic. Sci. 24:200-206.

Sakaguchi, T., and Shimojo, E. 1984. Inhibition of gastric motility induced by hepatic portal injections of D-glucose and its anomers. J. Physiol. 351:573-581.

Scheibner, J., Trendelenburg, A.U., Hein, L., Starke, K., and Blandizzi, C., 2002. Alpha 2adrenoceptors in the enteric nervous system: a study in alpha 2A-adrenoceptordeficient mice. Br. J. Pharmacol. 135:697-704.

Schemann, M., Rohn, M., and Michel, K. 2008. Motor control of the stomach. Eur. Rev. Med. Pharmacol. Sci. 12(Suppl 1):41-51.

Shi, M., Jones, A.R., Niedringhaus, M.S., Pearson, R.J., Biehl, A.M., Ferreira, M., Jr., Sahibzada, N., Verbalis, J.G., and Gillis, R.A. 2003. Glucose acts in the CNS to regulate gastric motility during hypoglycemia. Am. J. Physiol. Regul. Integr. Comp. Physiol. 285:1192-1202.

Tack, J. 2008. Prokinetics and fundic relaxants in upper functional GI disorders. Curr. Opin. Pharmacol. 8:690-696.

Takahashi, T., Tsuchida, D., and Pappas, T.N., 2007. Central effects of morphine on GI motility in conscious dogs. Brain Res. 1166:29-34.

Takeuchi, K., Miyazawa, T., Tanaka, A., Kato, S., and Kunikata, T. 2002. Pathogenic importance of intestinal hypermotility in NSAID-induced small intestinal damage in rats. Digestion 66:30-41.

Takeuchi, K., Niida, H., Ohuchi, T., and Okabe, S. 1994. Influences of urethane anesthesia on indomethacin-induced gastric mucosal lesions in rats. Relation to blood glucose levels. Dig. Dis. Sci. 39:2536-2542.

Umezawa, T., Guo, S., Jiao, Y., and Hisamitsu, T. 2003. Effect of clonidine on colonic motility in rats. Auton. Neurosci. 107:32-36.

Yuasa, H., and Watanabe, J. 1994. Influence of urethane anesthesia and abdominal surgery on gastrointestinal motility in rats. Biol. Pharm. Bull. 17:1309-1312. 
Zádori, Z.S., Shujaa, N., Fülöp, K., Dunkel, P., and Gyires, K. 2007. Pre- and postsynaptic mechanisms in the clonidine- and oxymetazoline-induced inhibition of gastric motility in the rat. Neurochem. Int. 51:297-305.

Zhou, S.Y., Lu, Y.X., and Owyang, C. 2008. Gastric relaxation induced by hyperglycemia is mediated by vagal afferent pathways in the rat. Am. J. Physiol. Gastrointest. Liver Physiol. 294:1158-1164. 


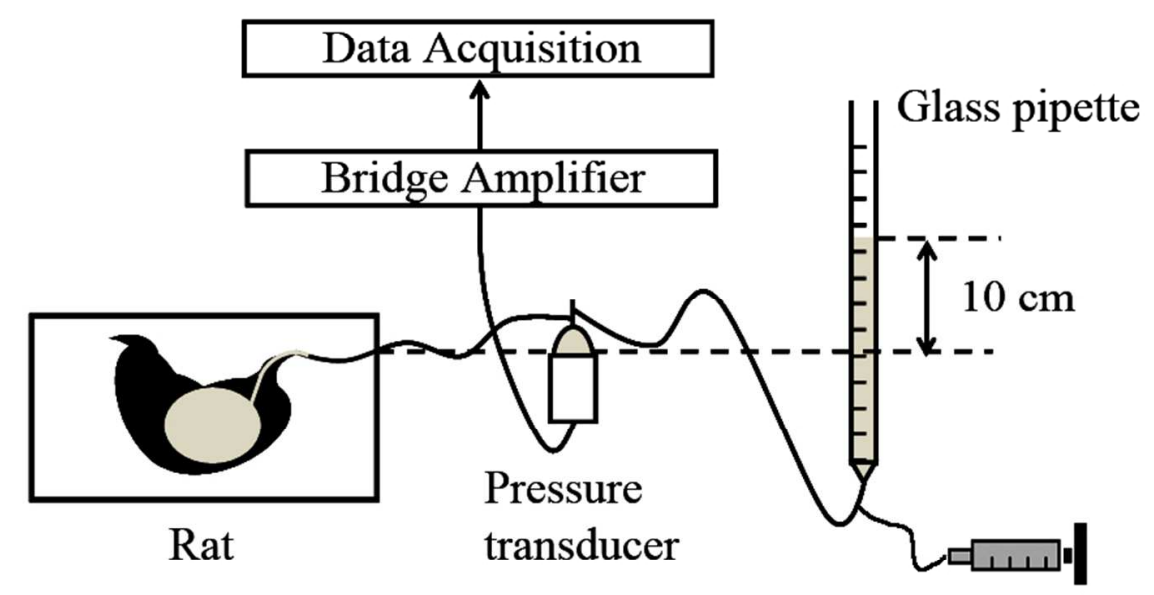

Scheme illustrating the setup for measuring intragastric pressure. The intragastric balloon is filled with water (grey colour) and connected to a pressure transducer with a polyethylene tube. The transducer is connected to a glass pipette, in which the height of the water column is set to $10 \mathrm{~cm}$ above the membrane of the transducer and the xiphoid process of the rat (providing an intragastric pressure $10 \mathrm{cmH} 2 \mathrm{O}$ ). $352 \times 211 \mathrm{~mm}(72 \times 72 \mathrm{DPI})$ 


\section{A}
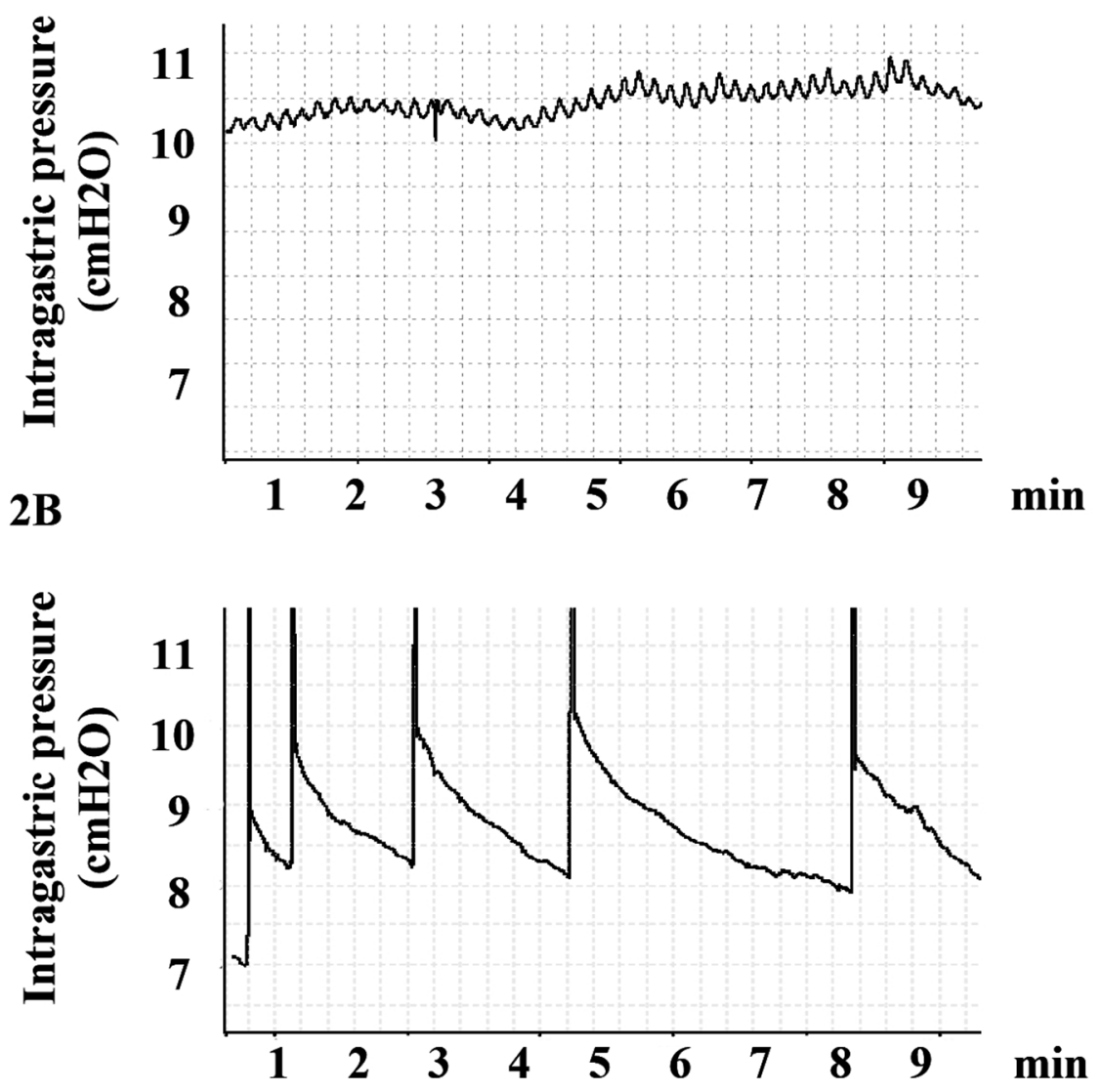

\footnotetext{
Representative experimental traces illustrating the stable intragastric pressure (Fig. 2A) and the constantly decreasing pressure (in spite of repeated correction with water injection) due to wrong localization of the balloon (Fig. 2B).

$469 \times 469 \mathrm{~mm}(72 \times 72 \mathrm{DPI})$
} 
A
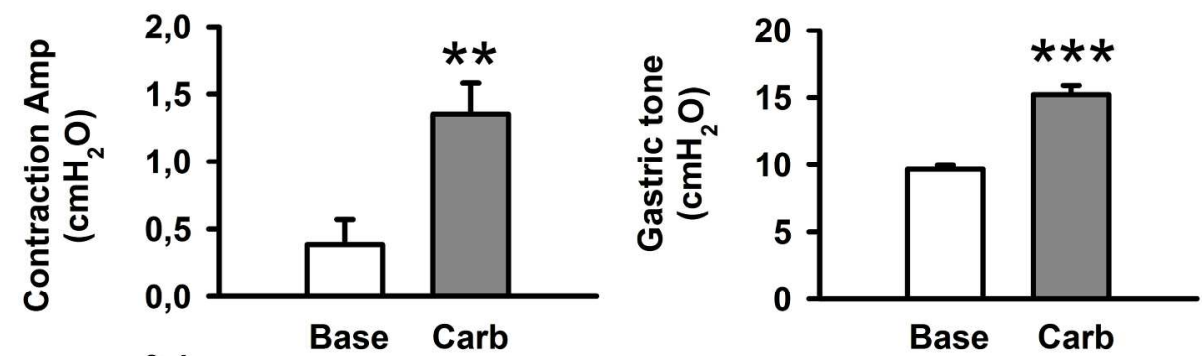

B
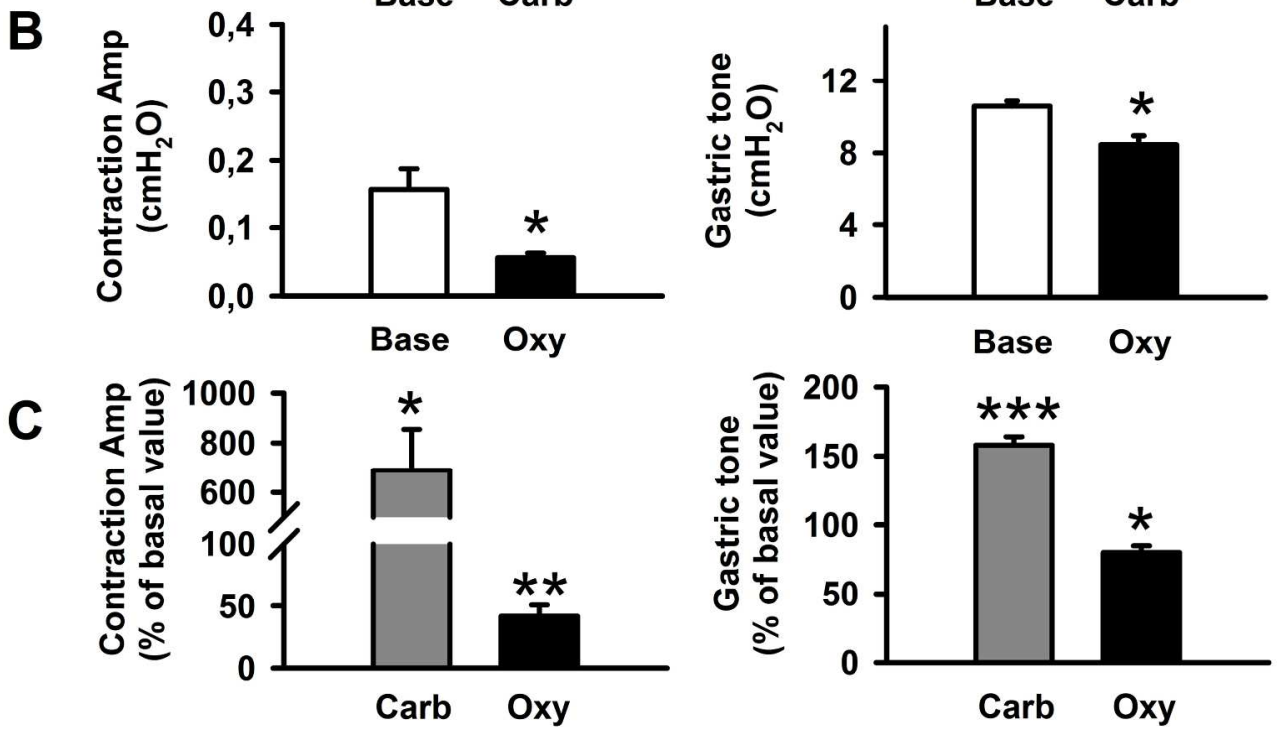

The effects of carbachol $(0.025 \mathrm{mg} / \mathrm{kg}$ i.v., $\mathrm{n}=7)$ and oxymetazoline $(0.5 \mathrm{mg} / \mathrm{kg}$ i.v., $\mathrm{n}=5)$ on contraction amplitude and gastric tone in urethane-anaesthetized rats. Panel $C$ shows the relative changes from baseline values. Each column represents mean \pm S.E.M. ${ }^{*} p<0.05, * * p<0.01, * * * p<0.001$ compared to basal values (Student's t-test, paired). $219 \times 197 \mathrm{~mm}(300 \times 300$ DPI $)$ 
Table 1.

Some studies using the rubber balloon method in anaesthetized rats.

\begin{tabular}{|c|c|c|c|c|}
\hline Animal & $\begin{array}{l}\text { Weight } \\
\text { (g) }\end{array}$ & $\begin{array}{l}\text { Applied } \\
\text { anesthetic }\end{array}$ & $\begin{array}{l}\text { Standardized basal } \\
\text { intragastric pressure } \\
\left(\text { converted to } \mathrm{cmH}_{2} \mathrm{O}\right)\end{array}$ & Reference \\
\hline $\begin{array}{l}\text { Male Wistar } \\
\text { rat }\end{array}$ & $260-280$ & Urethane & $11-12$ & Fülöp et al., 2005 \\
\hline $\begin{array}{l}\text { Male Wistar } \\
\text { rat }\end{array}$ & $250-350$ & Urethane & $9.5-10.5$ & Zádori et al., 2007 \\
\hline $\begin{array}{l}\text { Male Sprague- } \\
\text { Dawley rat }\end{array}$ & $250-300$ & Urethane & $5-10$ & Zhou et al., 2008 \\
\hline $\begin{array}{l}\text { Male Sprague- } \\
\text { Dawley rat }\end{array}$ & $200-390$ & $\begin{array}{l}\text { Ketamine }+ \\
\text { Xylazine }\end{array}$ & 5 & Krowicki and Hornby, 2000 \\
\hline $\begin{array}{l}\text { Male Sprague- } \\
\text { Dawley rat }\end{array}$ & $300-400$ & $\begin{array}{l}\text { Urethane }+\alpha- \\
\text { chloralose }\end{array}$ & $5.4-13.6$ & Shi et al., 2003 \\
\hline $\begin{array}{l}\text { Male rat } \\
\text { (unspecified } \\
\text { strain) }\end{array}$ & $250-300$ & Pentobarbital & $7.9-10$ & $\begin{array}{l}\text { Sakaguchi and Shimojo, } \\
1984\end{array}$ \\
\hline $\begin{array}{l}\text { Male Sprague- } \\
\text { Dawley rat }\end{array}$ & $250-350$ & $\begin{array}{l}\text { Urethane }+\alpha- \\
\text { chloralose }\end{array}$ & $10.8-16.3$ & Cruz et al., 2006 \\
\hline $\begin{array}{l}\text { Male Wistar } \\
\text { rat }\end{array}$ & $350-400$ & Urethane & 10 & Nagata and Osumi, 1990 \\
\hline $\begin{array}{l}\text { Male Sprague- } \\
\text { Dawley rat }\end{array}$ & $250-350$ & $\begin{array}{l}\text { Urethane }+\alpha- \\
\text { chloralose }\end{array}$ & $8.1-20.4$ & Ferreira Jr. et al., 2002 \\
\hline
\end{tabular}

